\section{Effect of Phosphoric Acid on Digitalis Compounds}

IT has been shown by $\operatorname{Cox}^{1}$ that pregnane- $3 \alpha, 17 \alpha$, $20 \alpha$-triol (pregnanetriol) and related compounds react with 70 per cent ortho-phosphoric acid to produco a brilliant fluorescence. Herman and Bruton ${ }^{2,3}$ have shown that pregnanetriol and related compounds and digitalis compounds react intensely with antimony pentachloride, which thus can be used as a paper chromatographic detecting agent. Sinco pregnanetriol reacts with both phosphoric acid and antimony pentachloride, by analogy, those storoids which react strongly with antimony pentachloride could be expected to react with 70 per cent ortho-phosphoric acid. Heftmann et al. ${ }^{4}$ have noted briefly that aniline-phosphoric acid is useful as a detecting agent for cardiae glycosides.

We have applied ortho-phosphoric acid to digitalis compounds and other steroids and have found that the natural fluorescence of the digitalis compounds under ultra-violet light is markedly enhanced. Each steroid was dissolved in chloroform and applied to

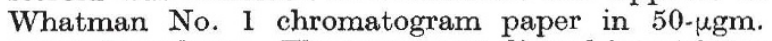
amounts or less. The paper was dipped into 70 per cent orthophosphoric acid and placed on a sheet of tinfoil. The paper was examined in visible and ultraviolet light ( 366 and $254 \mathrm{~m} \mu$ ) before and after heating at $80^{\circ} \mathrm{C}$. for $5 \mathrm{~min}$.

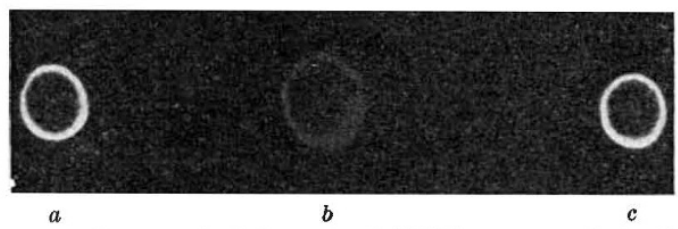

Fig. 1. Fiuorescent photograph of digitalis compounds treated with 70 per cent orthophosphoric acid. The compounds are: $a$, digitoxigenin; $b$, digoxin; $c$, dígitoxin

Table 1 indicates the results obtained with digitalis compounds and other steroids and related compounds. Fig. 1 is a fluorescent photograph of the digitalis compounds treated with 70 per cent ortho-phosphoric acid. The Whatman No. 1 paper containing the treated digitalis compounds was placed on type IF contrast 5 Haloid photographic paper (Xerox Corp., Rochester, New York) and exposed for 5 sec. at approximately 18 in. using a $254 \mathrm{~m} \mu$ ultra-violet light ${ }^{5}$. Both digitoxin and digitoxigenin fluoresce with a bright yellow colour and are reproduced well on the Haloid photographic paper. The digoxin fluoresces with a bright blue colour but appears much less intensely in the fluorescent photograph. Haloid photographic paper is insensitivo to wave-lengths of light beyond $450 \mathrm{~m} \mu$ so that fluorescence at wavelengths beyond 450 mu ean be recorded as an unexposed area.

We were able to detect a minimum of $10 \mu \mathrm{gm}$. of each of the three digitalis compounds in visible light using 70 per cent phosphoric acid. With ultra-violet light $(366 \mathrm{~m} \mu)$ we could detect a minimum of $5-\mu \mathrm{gm}$. with the fluorescence being more brilliant after heating.

This technique should be useful as a detecting method for digitalis compounds.

\section{Joseph BRUton \\ Robert H. Herman \\ LLOYd F. Clayton}

Department of Metabolism, Division of Medicine,

Walter Reed Army Institute of Research, Washington 12, D.C.

${ }^{2}$ Cox, R. I., J. Biol. Chem., 234, 1693 (1959).

${ }^{2}$ Herman, R. H., and Bruton, J., Nature, 190, 444 (1961).

s Herman, R. H., Nature, 190, 268 (1961).

4 Heftmann, E., Berner, P., Hayden, A. L., Miller, H. K., and Mosettig, E., Arch.'Biochem. Biophys., 51, 329 (1954).

- Herman, R. H., Clayton, L. E., and Bruton, J., Nature, 193, 169 (1962).

\section{O-Methylation in Fish}

DURING an investigation of the fate of some foreign organic compounds in fish, tho metabolism of 3,4-dihydroxyphenylacetic acid (homoprotocatechuic acid) was investigated with the purpose of obtaining some information on methylation reactions in these animals. DeEds et al. ${ }^{1}$ have noted that this compound is methylated at the 3 -hydroxyl group in rats and rabbits. A later report by Scheline et al..$^{2}$ showed that homoprotocatechuic acid labelled with carbon-14 fed to rabbits at a dose-level of $100 \mathrm{mgm}$. $/ \mathrm{kgm}$. resulted in about 85 per cent of the radioactivity being excreted in the urine within $\mathbf{4 4} \mathrm{hr}$. While the main excretory product was the original acid, nearly six por cent of the dose was found as 4-hydroxy-3-methoxyphenylacetic acid (homovanillic acid).

In the experiments described here 12 cod, Gadus callarias, weighing 420-1,370 gm. (average 740 gm.) were given homoprotocatechuic acid dissolved in saline. The dose-levels ranged from 35 to $120 \mathrm{mgm}$./ $\mathrm{kgm}$. (average $72 \mathrm{mgm}$./kgm.) and the compound was injected intraperitoneally (nine animals) and intramuscularly (three animals). The method used for identifying metabolites was similar in part to that of Wood $^{3}$ and consisted of placing the treated fish in a small plastic tank containing $5 \mathrm{l}$. of water. The water was aerated and maintained at $10^{\circ} \mathrm{C}$. by keeping the tank in a constant flow of cold water. After $20 \mathrm{hr}$. the

Table 1. Efrect of Phospionic Aord on Drgitalis Compounds and Orafr Steroids and Reiated Compounds

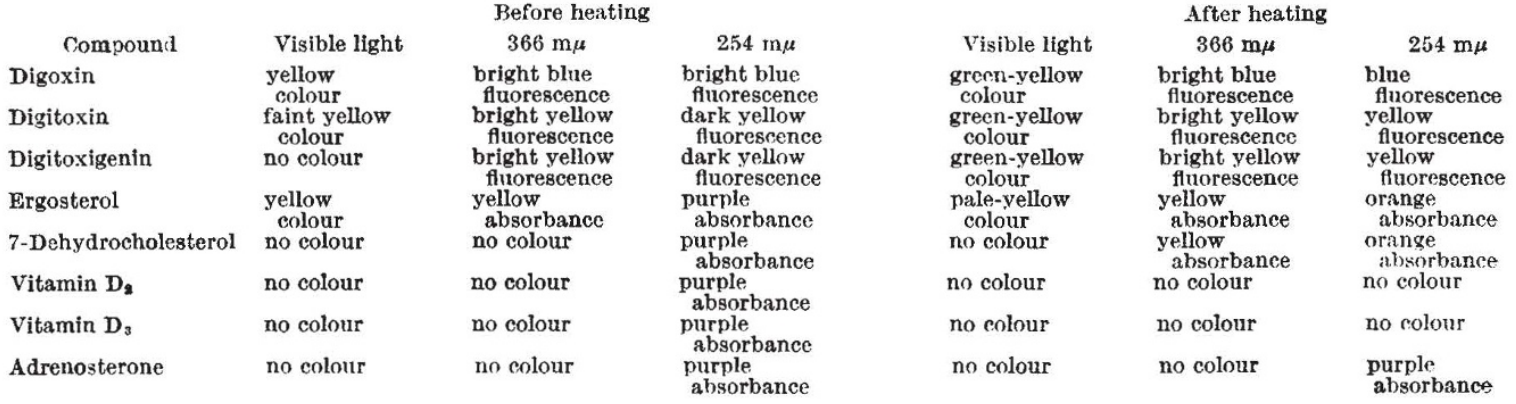

